\title{
Analisis Pola Rekrutmen Prajurit TNI AL Tahun 2020 Pada Satuan Pendidikan Sorong Dalam Rangka Penyediaan Prajurit Koarmada III
}

\author{
Andri Yusuf Kristmas Lakipundu Rassa ${ }^{1^{*}}$, Amin Lestari ${ }^{1}$ \\ ${ }^{1}$ Sekolah Staf dan Komando Angkatan Laut (SESKOAL) \\ Jl. Ciledug Raya No 2, Kompleks Seskoal Kebayoran Lama Kota Jakarta \\ *a.yusuf.rassa@gmail.com \\ DOI: https://doi.org/10.21107/rekayasa.v14i2.11293
}

\begin{abstract}
ABSTRAK
The study aims to improve the quality and quantity of Indonesian Navy human resources in Eastern Indonesia, especially in the working area of the Fleet Command III, so the recruitment of Indonesian Navy soldiers will fill the needs of personnel in Eastern Indonesia. The object of research in the form of individuals are the officers or personnel officers who handle the recruitment of candidates of the Indonesian Navy soldiers. As for the object of research in the form of organizations, namely Spersal, Lapetal Disminpersal, Panda Lantamal X Jayapura, Panda Lantamal XI Merauke and Panda Lantamal XIV Sorong. This study uses the following analytical techniques: grouping data based on the characteristics of informants, conducting a qualitative approach to find out in detail how descriptive study of recruitment patterns in each Panda, then combining literature review, data from the reality in the field, and the experience of informants to gain a general knowledge of the recruitment pattern in the Sorong Education Units. The results showed that the recruitment pattern at the Sorong Educational Service which supervised Panda Lantamal X Jayapura, Panda Lantamal XI Merauke and Panda Lantamal XIV Sorong, had been going well, regardless of the obstacles they faced.
\end{abstract}

Keywords : Indonesian Navy, recruitment, patterns, education unit

\section{PENDAHULUAN}

Kepala Staf Angkatan Laut (Kasal) Laksamana TNI Yudo Margono, S.E., M.M., menyampaikan sembilan program prioritas dalam pembangunan kekuatan dan pembinaan kemampuan TNI Angkatan Laut yang salah satunya adalah pembangunan Sumber Daya Manusia (SDM) TNI AL. Untuk menghasilkan SDM yang profesional, modern dan tangguh maka pimpinan TNI AL melakukan pembinaan secara sistematis, terarah dan berkelanjutan yang meliputi Pembinaan Tenaga Manusia dan Pembinaan Personel prajurit TNI AL (Yusuf, 2014).

Pembinaan prajurit TNI AL ini sejalan dengan Visi TNI AL yaitu "Terwujudnya TNI AL yang Profesional, Modern dan Tangguh untuk mewujudkan Indonesia Maju yang Berdaulat, Mandiri dan Berkepribadian Berdasarkan Gotong Royong" sesuai dengan Keputusan Kasal nomor Kep 12554/ V/2020 tanggal 5 Juni 2020 tentang Kebijakan Perencanaan TNI Angkatan Laut Tahun 2021. Salah satu bentuk pembinaan tersebut adalah "penyediaan" yang

\section{Article History:}

Received: July, 15 ${ }^{\text {th }}$ 2021; Accepted: July, $31^{\text {st }} 2021$

Rekayasa ISSN: 2502-5325 has been Accredited by Ristekdikti (Arjuna) Decree: No. 23/E/KPT/2019 August 8th, 2019 effective until 2023 merupakan langkah awal dalam penyiapan SDM sesuai dengan kualitas dan kuantitas yang dibutuhkan untuk memenuhi kebutuhan personel TNI AL. Sebagai aset dalam kekuatan pertahanan matra laut yang memiliki prinsip "Men behind the gun", personel TNI AL haruslah merupakan orangorang pilihan berdasarkan proses rekrutmen yang baik (Rivai, 2015).

Dalam rangka memenuhi kebutuhan personel pengawak organisasi TNI AL maka Lembaga Penyediaan Tenaga Angkatan Laut (Lapetal) selaku Unit Pelaksana Teknis (UPT) dari Disminpersal melaksanakan Rekrutmen calon prajurit TNI AL melalui seleksi penerimaan yang dilaksanakan sepanjang tahun. Pada Tahun Anggaran (TA) 2020, sesuai dengan perintah Kasal untuk melaksanakan rekrutmen sekaligus pendidikan dasar militer di wilayah Indonesia Timur, maka Lapetal melaksanakan Rekrutmen khusus pengawak Kapal Perang Republik Indonesia (KRI) untuk memenuhi

\section{Cite this as:}

Rassa, A.Y.K.L \& Lestari, A. (2021). Analisis Pola Rekrutmen Prajurit TNI AL Tahun 2020 pada Satuan Pendidikan Sorong dalam rangka Penyediaan Prajutit Koarmada III. Rekayasa 14 (2). 263-271.

doi: https://doi.org/10.21107/rekayasa.v14i2. 11293.

(C) 2021 Andri Yusuf Kristmas Lapipundu Rassa, Amin Lestari 
kebutuhan personel di wilayah kerja Komando Armada III. Seleksi penerimaan yang dilaksanakan di Satuan Pendidikan (Satdik) Sorong yang berada di wilayah Komando Armada III. Satdik Sorong berada di bawah Komando Pembinaan Doktrin, Pendidikan dan Latihan TNI Angkatan Laut (Kodiklatal). Satdik Sorong adalah satdik yang pertama dibentuk di wilayah Timur yang berlokasi di Katapop, Sorong. Satdik ini membawahi tiga Panitia Daerah (Panda) yang terdiri dari Panda Lantamal $X$ Jayapura, Panda Lantamal XI Merauke dan Panda Lantamal XIV Sorong. Proses penyediaan calon prajurit TNI AL dilaksanakan dengan cara menyeleksi Caba Prajurit Karier Pria dan Wanita (Caba PK Pria/wanita) TNI AL dan calon Tamtama Prajurit Karier (Catam PK) TNI AL yang berasal dari putra dan putri asli daerah maupun pemuda dan pemudi Warga Negara Indonesia yang lahir, besar dan bersekolah di wilayah Papua.

Menurut Nawawi (2020) rekrutmen (penarikan) adalah proses mendapatkan sejumlah calon tenaga kerja yang kualifaid utuk jabatan/pekerjaan utama (produk lini dan penunjangnya) di lingkungan suatu organisasi/perusahaan. Menurut Tjutju Yuniarsih dan Suwanto (2009) rekrutmen adalah proses pencarian dan pemikatan para calon pegawai yang mampu bekerja di dalam organisasi. Yunarsih dan Suwatno (2009) menjelaskan bahwa perekrutan merupakan kegiatan untuk mendapatkan sejumlah pegawai, dari berbagai sumber berdasarkan kualifikasi yang dibutuhkan sehingga dapat menjalankan misi sebagai realisasi visi organisasi serta tujuannya. Menurut Rivai dan Sagala (2015) rekrutmen adalah proses menarik sebanyak mungkin kualifikasi pelamar untuk lowongan yang ada dan bukan diantisipasi. Ini merupakan pencarian bakat, pengejaran kelompok terbaik pelamar untuk posisi yang tersedia. Rekrutmen juga sering disebut dengan penarikan tenaga kerja yang merupakan proses pencarian calon karyawan yang benar-benar dianggap feasible (layak) untuk ditempatkan pada posisi tertentu dalam organisasi. Setelah proses rekrutmen selesai, maka selanjutnya adalah seleksi. Dimana seleksi merupakan penyaringan calon tenaga kerja menjadi tenaga kerja dalam sebuah organisasi yang tentunya dibutuhkan oleh organisasi tersebut dengan kriteria-kriteria seleksi yang ditetapkan oleh organisasi (Creswell, 2009).

Dengan beberapa kondisi di atas, maka peneliti tertarik untuk menganalisis sejauh mana Pola Rekrutmen prajurit TNI AL TA 2020 pada Satuan
Pendidikan Sorong terhadap Sumber Daya Manusia dalam rangka Penyediaan Prajurit TNI AL di Koarmada III. Hasil dari penelitian ini nantinya dapat memberikan masukan bagi pimpinan TNI AL untuk memprioritaskan meningkatkan animo pendaftaran dengan promosi dan sosialisasi terpadu dari Lapetal, Dispenal dan panitia daerah. Selanjutnya Disminpersal mengatur penempatan dokter spesialis serta perwira Jasmani di masing-masing Panda untuk memperlancar pelaksanaan tes. Dengan demikian peneliti mencoba meneliti Analisis Pola Rekrutmen Prajurit TNI AL TA 2020 Pada Satuan Pendidikan Sorong Dalam Rangka Penyediaan Prajurit TNI AL di Koarmada III.

\section{METODE PENELITIAN}

Penelitian ini merupakan jenis penelitian lapangan (Field Research) yaitu penelitian yang dilakukan dengan cara turun langsung ke lapangan untuk menggali dan meneliti data. Dalam hal ini objek penelitian berupa individu adalah pada pejabat atau Perwira Personel yang menangani rekrutmen calon prajurit TNI AL. Sedangkan untuk objek penelitian berupa organisasi yaitu Ban II Spersal, Lapetal Disminpersal, Panda Lantamal X Jayapura, Panda Lantamal XI Merauke dan Panda Lantamal XIV Sorong.

Sumber data primer yang digunakan oleh peneliti berasal dari hasil wawancara dengan pihakpihak yang terlibat dalam proses rekrutmen di Satdik Sorong. Sumber Data Primer yaitu data yang diperoleh secara langsung dari sumber data atau obyek penelitian sedangkan data sekunder adalah merupakan sumber data eksternal. Contoh data primer adalah dokumen-dokumen yang berkaitan dengan rekrutmen dari Mabesal, Lapetal maupun Panitia Daerah yang berada pada Satdik Sorong. Sedangkan contoh data sekunder adalah buku, buletin, jurnal, surat perintah, laporan maupun literatur ilmiah.

Penelitian ini menggunakan teknik analisa sebagai berikut: mengelompokan data berdasarkan karakteristik informan, melakukan pendekatan kualitatif untuk mengetahui secara detail bagaimana studi deskriptif pola rekrutmen pada tiap-tiap Panda, kemudian menggabungkan kajian pustaka, data dari kenyataan di lapangan dan pengalaman informan untuk mendapatkan pengetahuan umum terhadap pola rekrutmen yang terdapat pada Satdik Sorong. Setelah itu peneliti akan menganalisa strategi pola rekrutmen terbaik dengan menggunakan analisis SWOT (Strengths, 
Weaknesses, Opportunities and Threats) dalam rangka meningkatkan animo pendaftar calon prajurit TNI AL.

\section{HASIL DAN PEMBAHASAN}

Locus penelitian meliputi Spersal Mabesal yang berada di Jakarta, Lapetal Disminpersal di Jakarta dan Malang, Panda Lantamal X di Jayapura, Panda Lantamal XI di Merauke dan Panda Lantamal XIV di Sorong. Tabel 1 dibawah ini menunjukkan bahwa pada TA 2020, animo akhir untuk Panda Jayapura terdapat 231 orang Caba PK Pria dan 73 orang Caba PK Wanita, kemudian Panda Merauke dengan jumlah 104 orang Caba PK Pria dan 37 orang Caba PK Wanita dan terakhir adalah Panda Sorong dengan jumlah 442 orang Caba PK Pria dan 132 orang Caba PK Wanita. Animo akhir Catam PK TNI AL pada TA 2020 yang berasal dari tiga Panda dalam wilayah kerja Koarmada III dapat dilihat pada tabel 2 di bawah ini. Untuk Panda Jayapura, jumlah pendaftar untuk Catam PK TNI AL sejumlah 98 orang, kemudian Panda Merauke sejumlah 31 orang dan terakhir adalah Panda Sorong sejumlah 64 orang Catam PK TNI AL (Tabel 2).

Tabel 1. Rekapitulasi Caba PK Pria dan Wanita TNI $\mathrm{AL}$

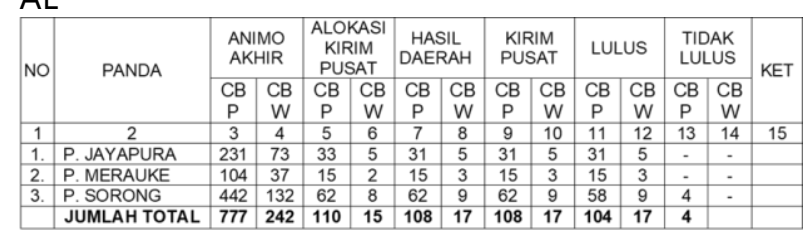

Tabel 2. Rekapitulasi Catam PK TNI AL

\begin{tabular}{|c|l|c|c|c|c|c|c|c|}
\hline \multirow{2}{*}{ No } & \multirow{2}{*}{ PANDA } & $\begin{array}{c}\text { ANIMO } \\
\text { AKHIR }\end{array}$ & $\begin{array}{c}\text { ALOKASI } \\
\text { KIRIM } \\
\text { PUSAT }\end{array}$ & $\begin{array}{c}\text { HASIL } \\
\text { DAERAH }\end{array}$ & $\begin{array}{c}\text { KIRIM } \\
\text { PUSAT }\end{array}$ & LULUS & $\begin{array}{c}\text { TIDAK } \\
\text { LULUS }\end{array}$ & \multirow{2}{*}{ KET } \\
\cline { 3 - 9 } & CATA & CATA & CATA & CATA & CATA & CATA & \\
\hline 1 & PANDA JAYAPURA & 98 & 63 & 32 & 32 & 31 & 1 & \\
\hline 2 & PANDA MERAUKE & 31 & 20 & 12 & 12 & 12 & - & \\
\hline 3 & PANDA SORONG & 64 & 42 & 42 & 42 & 37 & 5 & \\
\hline & JUMLAH TOTAL & 193 & 125 & 85 & 85 & 79 & 6 & \\
\hline
\end{tabular}

Panitia daerah yang ditugaskan dalam seleksi tingkat daerah dan seleksi tingkat pusat dalam melakukan proses rekrutmen tentunya berdasarkan pada telegram Kasal, surat perintah Kasal dan rencana kebutuhan personel TNI AL dari Ban II Binteman Spersal untuk melaksanakan penerimaan calon prajurit TNI AL tahun 2020 dalam hal ini pemenuhan prajurit pengawak KRI yang berasal dari wilayah kerja Komando Armada III atau calon prajurit putra dan putri asli daerah yang berasal dari Panda Lantamal X Jayapura, Panda Lantamal XI Merauke dan Panda Lantamal XIV Sorong. Pada tahun 2020 Satdik Sorong hanya membawahi 3 Panda kemudian pada tahun 2021 berubah menjadi Satdik 3 Sorong yang membawahi 5 Panda termasuk di dalamnya Panda Ambon dan Panda Ternate.

Berdasarkan hasil observasi yang dilakukan oleh peneliti, Ban II Binteman Spersal mempunyai tugas dan tanggung jawab saat pelaksanaan rekrutmen prajurit TNI AL yaitu membuat dan menyusun kebijakan-kebijakan bidang personel di lingkungan TNI $A L$, merencanakan dan mengendalikan kebutuhan personel TNI $A L$, mengawasi pelaksanaan kegiatan penerimaan personel, melaksanakan evaluasi terhadap pelaksanaan kegiatan seleksi penerimaan prajurit TNI AL. Sedangkan Lapetal mempunyai tugas dan tanggung jawab, yaitu menyusun dan melaksanakan kegiatan seleksi program Pendidikan pertama (Dikma) TNI AL, bertanggung jawab terhadap pelaksanaan seleksi sebagai bahan sidang serta pelaksanaan sidang komisi Pantukhir dalam menentukan calon prajurit TNI AL yang terpilih, melaporkan hasil pelaksanaan seleksi ke Disminpersal. Untuk Panda Lantamal yang terdiri dari Lantamal X Jayapura, Lantamal XI Merauke dan Lantamal XIV Sorong, masing-masing Panda melaksanakan seleksi tingkat daerah. Pemenuhan animo pendaftar pada masing-masing Panda tergantung pada kegiatan sosialisasi dan promosi yang dilaksanakan oleh Panda, terlepas dari giat sosialiasi dan promosi yang dilaksanakan oleh Lapetal melalui media sosial Instagram, Facebook dan website Lapetal, maupun melalui program promosi oleh Dispenal.

Tabel 3. Rekapitulasi Animo Akhir Caba PK TNI AL Satdik 3 Sorong

\begin{tabular}{|c|c|c|c|c|c|c|c|}
\hline \multirow{2}{*}{ NO } & \multirow{2}{*}{ PANDA } & \multicolumn{2}{|c|}{ ANIMO AKHIR } & \multicolumn{2}{c|}{ ANIMO AKHIR } & \multicolumn{2}{c|}{ PERSENTASE } \\
& & & TA 2020 & \multicolumn{2}{c|}{ TA 2021} & \multicolumn{2}{c|}{ TA 2021 (\%) } \\
\cline { 3 - 8 } & & $\mathrm{W}$ & $\mathrm{P}$ & $\mathrm{W}$ & $\mathrm{P}$ & $\mathrm{W}$ \\
\hline 1 & JAYAPURA & 231 & 73 & 269 & 47 & $16,45 \%$ & $-35,62 \%$ \\
\hline 2 & MERAUKE & 104 & 37 & 85 & 21 & $-18,27 \%$ & $-43,24 \%$ \\
\hline 3 & SORONG & 442 & 132 & 523 & 185 & $18,33 \%$ & $40,15 \%$ \\
\hline & TOTAL & $\mathbf{7 7 7}$ & $\mathbf{2 4 2}$ & $\mathbf{8 7 7}$ & $\mathbf{2 5 3}$ & $\mathbf{1 6 , 5 1 \%}$ & $\mathbf{- 3 8 , 7 1 \%}$ \\
\hline
\end{tabular}

Pada tahun anggaran 2020 terlihat bahwa animo untuk pendaftaran calon Bintara di Panda Sorong cukup besar dengan jumlah 442 Caba PK Pria dan 132 orang Caba PK Wanita mengalami peningkatan yang cukup signifikan di tahun 2021 menjadi 523 orang Caba PK Pria dan 185 orang Caba PK Wanita atau dengan kenaikan $18,33 \%$ dan $40,15 \%$. Sedangkan Panda Jayapura mengalami kenaikan pendaftaran Caba PK Pria menjadi 16,45 \% sedangan untuk Caba PK Wanita mengalami penurunan sebesar $-35,62 \%$. Kemudian terakhir dari Panda Merauke mengalamai penurunan animo 
untuk Caba PK Pria sebesar -18,27 \% dan -43,24 \% untuk Caba PK Wanita.

Tabel 4. Rekapitulasi Animo Akhir Catam PK TNI AL Satdik 3 Sorong

\begin{tabular}{|c|c|c|c|c|}
\hline NO & PANDA & $\begin{array}{c}\text { ANIMO AKHIR } \\
\text { TA } 2020\end{array}$ & $\begin{array}{c}\text { ANIMO AKHIR } \\
\text { TA } 2021\end{array}$ & $\begin{array}{c}\text { PERSENTASE } \\
\text { TA } 2021(\%)\end{array}$ \\
\hline 1 & JAYAPURA & 98 & 94 & $-4,08 \%$ \\
\hline 2 & MERAUKE & 31 & 29 & $-6,45 \%$ \\
\hline 3 & SORONG & 64 & 110 & $71,88 \%$ \\
\hline & TOTAL & 193 & 233 & $61,34 \%$ \\
\hline
\end{tabular}

Pada tahun anggaran 2021 terlihat bahwa animo untuk pendaftaran calon Tamtama PK TNI AL di Panda Sorong cukup besar dengan kenaikan sebesar $71,88 \%$. Sedangkan untuk Panda Jayapura dan Panda Merauke mengalami penurunan animo sebesar $-4,08 \%$ dan $-6,45 \%$ dari tahun anggaran 2020. Penurunan ini disebabkan oleh berapa faktor antara lain masih mewabahnya pandemi virus Covid-19 dan masih kurangnya informasi yang diterima oleh masyarakat terkait telah dibukanya pendaftaran khusus di Satdik 3 Sorong yang pada tahun 2021 ini diperluas hingga Ambon dan Ternate.

Kendala yang ditemukan berupa kekurangan Pemeriksa/Penguji yang akan melaksanakan seleksi di tingkat daerah dapat diantisipasi dengan melaksanakan koordinasi dengan tim Profesi serta melaksanakan penyesuaian jadwal seleksi masingmasing Panda sehingga kekurangan Pemeriksa/Penguji dapat tertutupi dan pada akhirnya seluruh pelaksanaan seleksi dapat berlangsung dengan lancar dan aman sesuai dengan jadwal yang telah ditetapkan. Selain itu dari Disminpersal berkoordinasi dengan tim Profesi pelaksana seleksi di daerah untuk menentukan jumlah personel yang dibutuhkan dalam pelaksanaan seleksi di Panda. Dari hasil koordinasi tersebut maka Disminpersal melaksanakan pergeseran personel untuk mengisi kekosongan tenaga Profesi yang akan bergabung dalam Pemeriksa/Penguji dalam pelaksanaan seleksi di Panda.

Berdasarkan data-data yang telah dikumpulkan melalui wawancara penelitian, observasi dan studi literatur, peneliti dapat membuat rumusan awal tentang faktor-faktor internal dan eksternal yang akan digunakan dalam analisis SWOT yaitu: Perkasal nomor 3 Tahun 2020 tentang Rekrutmen Bintara dan Tamtama, gaya kepemimpinan Kalapetal dalam jam tatap muka atau pengarahan sebelum pelaksanaan seleksi, Penunjukan tim Profesi yang masuk dalam Panitia Seleksi yang berkompeten, adanya pengawasan dalam rekrutmen, kurangnya inovasi dlam sosialisasi penerimaan Prajurit TNI AL, tidak adanya target animo Panda, tidak adanya anggaran khusus pembinaan calon prajurit di Panda, kemajuan teknologi informasi, adanya pembukaan Satdik Sorong, kebijakan TNI AL tentang rekrutmen di wilayah Indonesia Timur dimana yang menjadi prioritas adalah putra putri asli daerah, adanya wabah Covid-19 sehinggga kurangnya animo pendaftaran dari masyarakat setempat ditambah dengan adanya pengaruh OPM yang membuat para pemuda enggan bergabung menjadi prajurit TNI AL. Maka peneliti menyusun rumusan awal faktorfaktor SWOT sebagai berikut:

Tabel 5. Rumusan Awal Faktor-Faktor SWOT

\begin{tabular}{|c|l|}
\hline No & \multicolumn{1}{|c|}{ Pernyataan } \\
\hline 1 & $\begin{array}{l}\text { Perkasal nomor 3 tahun 2020 tentang } \\
\text { Rekrutmen Bintara dan Tamtama }\end{array}$ \\
\hline 2 & Gaya kepimimpinan Kalapetal \\
\hline 3 & $\begin{array}{l}\text { Penunjukan Tim Pemeriksa/Penguji sesuai } \\
\text { dengan kompetensinya }\end{array}$ \\
\hline 4 & Pakta Integritas dan Transparansi seleksi \\
\hline & \multicolumn{1}{|c|}{ Weaknesses (Kelemahan) } \\
\hline 5 & $\begin{array}{l}\text { Kurangnya inovasi dalam Sosialisasi } \\
\text { penerimaan prajurit TNI AL. }\end{array}$ \\
\hline 6 & Tidak Adanya target animo Panda \\
\hline 7 & $\begin{array}{l}\text { Tidak adanya anggaran khusus pembinaan } \\
\text { calon prajurit di Panda }\end{array}$ \\
\hline & \multicolumn{1}{|c|}{ Opportunities (Peluang) } \\
\hline 8 & Kemajuan Teknologi Informasi \\
\hline 9 & $\begin{array}{l}\text { Pembukaan Satdik khusus di wilayah } \\
\text { masing-masing }\end{array}$ \\
\hline 10 & $\begin{array}{l}\text { Jakren TNI AL tahun 2020 tentang } \\
\text { rekrutmen di wilayah Indonesia Timur }\end{array}$ \\
\hline 11 & $\begin{array}{l}\text { Rekrutmen dikhususkan pada putra dan } \\
\text { putri asli daerah }\end{array}$ \\
\hline & \multicolumn{1}{|c|}{ Threats (Ancaman) } \\
\hline 12 & Wabah Covid-19 \\
\hline 13 & $\begin{array}{l}\text { Kurangnya animo pendaftaran dari } \\
\text { masyarakat setempat }\end{array}$ \\
\hline 14 & $\begin{array}{l}\text { Pengaruh OPM sehingga para pemuda } \\
\text { tidak mau menjadi prajurit TNI AL }\end{array}$ \\
\hline
\end{tabular}

Peneliti kemudian melaksanakan wawancara dengan beberapa expert dari Lapetal dan Spersal dengan teknik Snowball untuk memperoleh data tentang faktor-faktor SWOT yang lebih tepat. 
Tabel 6. Hasil Penghitungan Bobot Faktor Internal Kekuatan (Strengths) dan Kelemahan (Weaknesses)

\begin{tabular}{|c|c|c|c|c|c|c|c|c|c|}
\hline \multirow[t]{3}{*}{ NO } & \multirow{3}{*}{$\begin{array}{l}\text { Internal Factor Strategic Analysis } \\
\text { (IFAS) }\end{array}$} & \multicolumn{5}{|c|}{ Skala } & \multirow[t]{3}{*}{ JML } & \multirow[t]{3}{*}{ TOTAL } & \multirow[t]{3}{*}{ NORM } \\
\hline & & TP & SDP & CP & $\mathbf{P}$ & SP & & & \\
\hline & & 0 & 0.25 & 0.5 & 0.75 & 1 & & & \\
\hline $\mathbf{S}$ & Kekuatan (Strenghts) & & & & & & & & \\
\hline 1 & $\begin{array}{l}\text { (S1) Peraturan Kasal nomor } 3 \text { tahun } 2020 \\
\text { tentang Rekrutmen Bintara dan Tamtama }\end{array}$ & & & 1 & 4 & 5 & 10 & 8.5 & 0.15 \\
\hline 2 & (S2) Pengawasan terhadap Tim Seleksi & & 2 & 2 & 4 & 2 & 10 & 6.5 & 0.11 \\
\hline 3 & $\begin{array}{l}\text { (S3) Penunjukan Tim Pemeriksa /Penguji } \\
\text { sesuai dengan kompetensinya }\end{array}$ & & & 1 & 5 & 4 & 10 & 8.25 & 0.14 \\
\hline 4 & $\begin{array}{l}\text { (S4) Pakta Integritas dan Transparansi } \\
\text { seleksi }\end{array}$ & & & 5 & 3 & 2 & 10 & 9 & 0.16 \\
\hline $\mathbf{W}$ & Kelemahan (Weaknesses) & & & & & & & & \\
\hline 1 & $\begin{array}{l}\text { (W1) Kurangnya inovasi dalam Sosialisasi } \\
\text { penerimaan prajurit TNI AL }\end{array}$ & & 2 & 2 & 5 & 1 & 10 & 6.25 & 0.11 \\
\hline 2 & (W2) Kompetensi pejabat Personel & 1 & 4 & 1 & 4 & & 10 & 4.5 & 0.08 \\
\hline 3 & $\begin{array}{l}\text { (W3) Tidak adanya Reward and } \\
\text { Punishment }\end{array}$ & & 3 & 3 & 4 & & 10 & 5.25 & 0.09 \\
\hline 4 & $\begin{array}{l}\text { (W4) Tidak adanya anggaran khusus } \\
\text { pembinaan calon prajurit di Panda }\end{array}$ & & 1 & & 2 & 7 & 10 & 8.75 & 0.15 \\
\hline \multicolumn{8}{|c|}{ Jumlah } & 57 & 1 \\
\hline
\end{tabular}

Tabel 7. Hasil Penghitungan Bobot Faktor Eksternal Peluang (Opportunities) dan Ancaman (Threats)

\begin{tabular}{|c|c|c|c|c|c|c|c|c|c|}
\hline \multirow[t]{3}{*}{ NO } & \multirow{3}{*}{$\begin{array}{l}\text { Eksternal Factor Strategic Analysis } \\
\text { (EFAS) }\end{array}$} & \multicolumn{5}{|c|}{ Skala } & \multirow[t]{3}{*}{ JML } & \multirow[t]{3}{*}{ TOTAL } & \multirow[t]{3}{*}{ NORM } \\
\hline & & TP & SDP & CP & $\mathbf{P}$ & SP & & & \\
\hline & & 0 & 0.25 & 0.5 & 0.75 & 1 & & & \\
\hline 0 & Peluang (Opportunities) & & & & & & & & \\
\hline 1 & (O1) Kemajuan Teknologi Informasi & & & & 2 & 8 & 10 & 9.5 & 0.17 \\
\hline 2 & (O2) Pembukaan Satdik Sorong & & 2 & 2 & 6 & & 10 & 6 & 0.11 \\
\hline 3 & $\begin{array}{l}\text { (O3) Jakren TNI AL } 2020 \text { Rekrutmen di } \\
\text { wilayah Indonesia Timur }\end{array}$ & & & & 1 & 9 & 10 & 9.75 & 0.17 \\
\hline 4 & (O4) Validasi Organisasi TNI AL & & 1 & 2 & 7 & & 10 & 6.5 & 0.11 \\
\hline $\mathbf{T}$ & Ancaman (Threats) & & & & & & & & \\
\hline 1 & (T1) Wabah Covid-19 & & 1 & & 3 & 6 & 10 & 8.5 & 0.15 \\
\hline 2 & $\begin{array}{l}\text { (T2) Minimnya animo pendaftaran dari } \\
\text { masyarakat setempat }\end{array}$ & & 1 & & 4 & 5 & 10 & 8.25 & 0.15 \\
\hline 3 & (T3) Kesiapan calon peserta seleksi & 2 & 5 & 2 & 1 & & 10 & 3 & 0.05 \\
\hline 4 & $\begin{array}{l}\text { (T4) Pengaruh OPM sehingga para pemuda } \\
\text { enggan menjadi TNI AL }\end{array}$ & 1 & 2 & 2 & 5 & & 10 & 5.25 & 0.09 \\
\hline \multicolumn{8}{|c|}{ Jumlah } & 57 & 1 \\
\hline
\end{tabular}

Teknik snowball adalah metode sampling di mana sampel diperoleh melalui proses bergilir dari satu responden ke responden yang lain. Setelah mendapatkan Faktor-faktor IFAS (Internal Strategic Factor Analysis) dan EFAS (Eksternal Strategic Factor Analysis) menggunakan teknik snowball untuk memperoleh data tentang faktor-faktor SWOT yang lebih tepat, selanjutnya peneliti melaksanakan analisis Pola Rekrutmen pada Satdik Sorong menggunakan metode SWOT dengan menggunakan bantuan software Microsoft Excel. Berdasarkan skala nilai dalam penghitungan bobot menurut Freddy Rangkuti (2016), penilaian menggunakan skala 0 sampai dengan 1 dengan keterangan sebagai berikut:

$$
\begin{array}{ll}
0 & =\mathrm{TP} \text { (Tidak Penting) } \\
0,25 & =\mathrm{SDP} \text { (Sedikit Penting) } \\
0,5 & =\mathrm{CP} \text { (Cukup Penting) }
\end{array}
$$




$$
\begin{array}{ll}
0,75 & =\mathrm{P}(\text { Penting }) \\
1 & =\mathrm{SP}(\text { Sangat Penting })
\end{array}
$$

External Factors Analysis Strategy (EFAS) dengan perkalian antara nilai bobot dan rating (Tabel $10 \&$

\begin{tabular}{|c|c|c|c|c|c|c|c|c|}
\hline \multirow[t]{3}{*}{ NO } & \multirow[t]{3}{*}{ Internal Factor Strategic Analysis (IFAS) } & \multicolumn{4}{|c|}{ NILAI SKALA } & \multirow[t]{3}{*}{ JML } & \multirow[t]{3}{*}{ TOTAL } & \multirow{3}{*}{$\begin{array}{l}\text { RATA } \\
\text { RATA }\end{array}$} \\
\hline & & $\mathbf{L}$ & $\mathbf{S}$ & $\mathbf{K}$ & SK & & & \\
\hline & & 1 & 3 & 3 & 4 & & & \\
\hline A & Kekuatan (Strenghts) & & & & & & & \\
\hline 1. & $\begin{array}{l}\text { (S1) Perkasal no } 3 \text { tahun } 2020 \text { tentang } \\
\text { Rekrutmen Bintara dan Tamtama }\end{array}$ & & 3 & & 7 & 10 & 34 & 3.4 \\
\hline 2. & (S2) Pengawasan terhadap Tim Seleksi & & 7 & 3 & & 10 & 23 & 2.3 \\
\hline 3. & $\begin{array}{l}\text { (S3) Penunjukan Tim Pemeriksa/Penguji sesuai } \\
\text { dengan kompetensinya }\end{array}$ & & 5 & 5 & & 10 & 25 & 2.5 \\
\hline 4. & (S4) Pakta Integritas dan Transparansi seleksi & & 3 & 7 & & 10 & 27 & 2.7 \\
\hline B & Kelemahan (Weaknesses) & & & & & & & \\
\hline 1. & $\begin{array}{l}\text { (W1) Kurangnya inovasi dalam Sosialisasi } \\
\text { penerimaan prajurit TNI AL }\end{array}$ & & 5 & 5 & & 10 & 25 & 2.5 \\
\hline 2. & (W2) Kompetensi pejabat Personel & & 8 & 2 & & 10 & 22 & 2.2 \\
\hline 3. & (W3) Tidak adanya Reward and Punishment & & 7 & 3 & & 10 & 23 & 2.3 \\
\hline 4. & $\begin{array}{l}\text { (W4) Tidak adanya anggaran khusus pembinaan } \\
\text { calon prajurit di Panda }\end{array}$ & & 2 & 8 & & 10 & 28 & 2.8 \\
\hline
\end{tabular}

Tabel 8. Hasil Penghitungan Rating Faktor Strengths dan Weaknesses

\begin{tabular}{|c|c|c|c|c|c|c|c|c|}
\hline \multirow[t]{3}{*}{ NO } & \multirow[t]{3}{*}{ Eksternal Factor Strategic Analysis (EFAS) } & \multicolumn{4}{|c|}{ NILAI SKALA } & \multirow[t]{3}{*}{ JML } & \multirow[t]{3}{*}{ TOTAL } & \multirow{3}{*}{$\begin{array}{l}\text { RATA- } \\
\text { RATA }\end{array}$} \\
\hline & & $\mathbf{L}$ & $\mathbf{S}$ & $\mathbf{K}$ & SK & & & \\
\hline & & 1 & 2 & 3 & 4 & & & \\
\hline $\mathbf{A}$ & Peluang (Opportunities) & & & & & & & \\
\hline 1. & (O1) Kemajuan Teknologi Informasi & & 1 & 3 & 6 & 10 & 35 & 3.5 \\
\hline 2. & (O2) Pembukaan Satdik Sorong & & 4 & 6 & & 10 & 26 & 2.6 \\
\hline 3. & $\begin{array}{l}\text { (O3) Jakren TNI AL } 2020 \text { Rekrutmen di wilayah } \\
\text { Indonesia Timur }\end{array}$ & & & 2 & 8 & 10 & 38 & 3.8 \\
\hline 4. & (O4) Validasi Organisasi TNI AL & & 5 & 5 & & 10 & 25 & 2.5 \\
\hline B & Ancaman (Threats) & & & & & & & \\
\hline 1. & $\begin{array}{l}\text { (T1) Masyarakat belum mengenal keberadaan } \\
\text { TNI AL }\end{array}$ & & & 4 & 6 & 10 & 36 & 3.6 \\
\hline 2. & $\begin{array}{l}\text { (T2) Minimnya animo pendaftaran dari } \\
\text { masyarakat setempat }\end{array}$ & & 3 & 7 & & 10 & 27 & 2.7 \\
\hline 3 & (T3) Kesiapan calon peserta seleksi & 4 & 6 & & & 10 & 16 & 1.6 \\
\hline 4 & $\begin{array}{l}\text { (T4) Pengaruh OPM sehingga para pemuda } \\
\text { enggan menjadi TNI AL }\end{array}$ & 2 & 6 & 2 & & 10 & 20 & 2 \\
\hline
\end{tabular}

Tabel 9. Hasil Penghitungan Rating Faktor Opportunities dan Threats

Dalam penghitungan nilai rating faktor-faktor SWOT, peneliti menggunakan jumlah total responden 10 orang yaitu Kalapetal, Pabandya Daldiakuatkuat Spersal, Kasiops Lapetal, Kasijian Lapetal, Kasi Mindia lapetal, Kasubsirenops Lapetal, Kasubsiring Lapetal, Kasubsimingar Lapetal dan Kasubsi Evalap Lapetal. Skala nilai dalam penghitungan rating, penilai menggunakan nilai skala 1 (poor) sampai dengan 4 (outstanding) berdasarkan Rangkuti (2016). Setelah penghitungan nilai bobot dan rating, peneliti menghitung nilai Skor Internal Factors Analysis Summary (IFAS) dan
11).

Setelah total nilai pada faktor-faktor SWOT didapatkan, langkah selanjutnya yaitu menghitung selisih antara Nilai Kekuatan (Strengths) dengan Kelemahan (Weaknesses) sebagai sumbu $X$ dan Selisih Nilai Peluang (Opportunities) dan Ancaman (Threats) sebagai sumbu Y. Didapatkan selisih nilai IFAS sebesar 0,47 (X) dan selisih nilai EFAS sebesar 0,85 (Y). Berdasarkan selisih nilai tersebut didapatkan titik kordinat terletak di kuadran I pada kuadran SWOT (Gambar 1). 
Tabel 10. Hasil Penghitungan Nilai IFAS

\begin{tabular}{|c|c|c|c|c|}
\hline No & IFAS & Вовот & RATING & NILA \\
\hline $\mathbf{S}$ & Kekuatan (Strengths) & & & \\
\hline 1 & $\begin{array}{l}\text { (\$1) Peraturan Kasal nomor } 3 \text { tahun } 2020 \text { tentang Rekrutmen Bintara } \\
\text { dan Tamtama }\end{array}$ & 0.15 & 3.4 & 0.51 \\
\hline 2 & (S2) Pengawasan terhadap Tim Seleksi & 0.11 & 2.3 & 0.26 \\
\hline 3 & $\begin{array}{l}\begin{array}{l}\text { (S3) Penunjukan Tim Pemeriksa/Penguji sesuai dengan } \\
\text { kompetensinya }\end{array} \\
\end{array}$ & 0.14 & 2.5 & 0.36 \\
\hline \multirow[t]{2}{*}{4} & (S4) Pakta Integritas dan Transparansi seleksi & 0.16 & 2.7 & 0.43 \\
\hline & Total & & & 1,56 \\
\hline $\mathbf{w}$ & Kelemahan (Weaknesses) & BOBOT & RATING & NILA \\
\hline 1 & (W1) Kurangnya inovasi dalam Sosialisasi penerimaan prajurit TNI AL & 0.11 & 2.5 & 0.27 \\
\hline 2 & (W2) Kompetensi pejabat Personel & 0.08 & 2.2 & 0.17 \\
\hline 3 & (W3) Tidak adanya Reward and Punishment & 0.09 & 2.3 & 0.21 \\
\hline \multirow[t]{2}{*}{4} & $\begin{array}{l}\text { (W4) Tidak adanya anggaran khusus pembinaan calon prajurit di } \\
\text { Panda }\end{array}$ & 0.15 & 2.8 & 0.43 \\
\hline & Total & & & 1,09 \\
\hline
\end{tabular}

Tabel 11. Hasil Penghitungan Nilai EFAS

\begin{tabular}{|c|c|c|c|c|}
\hline NO & 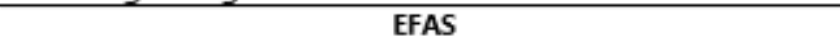 & BOBOT & RATING & NILAI \\
\hline 0 & Peluang (Opportunities) & & & \\
\hline 1 & (O1) Kemajuan Teknologi Informasi & 0.17 & 3.4 & 0.57 \\
\hline 2 & (O2) Pembukaan Satcik Sorong & 0.11 & 2.3 & 0.24 \\
\hline 3 & (O3) Jakren TNI AL 2020 Rekrutmen di wilayah Indonesia Timur & 0.17 & 2.5 & 0.43 \\
\hline \multirow[t]{2}{*}{4} & (O4) Validasi Organisasi TNI AL & 0.11 & 2.7 & 0.31 \\
\hline & Total & & & 1.55 \\
\hline $\mathbf{T}$ & Ancaman (Threats) & BOBOT & RATING & NILAI \\
\hline 1 & (T1) Masyarakat belum mengenal keberadaan TNI AL & 0.11 & 1 & 0.11 \\
\hline 2 & (T2) Minimnya animo pendaftaran dari masyarakat setempat & 0.08 & 2 & 0.16 \\
\hline 3 & (T3) Kesiapan calon peserta seleksi & 0.09 & 3 & 0.28 \\
\hline \multirow[t]{2}{*}{4} & (T4) Pengaruh OPM sehingga para pemuda enggan menjadi TNI AL & 0.15 & 1 & 0.15 \\
\hline & Total & & & 0.70 \\
\hline
\end{tabular}

Tabel 12. Kordinat Hasil Penghitungan IFAS dan

\begin{tabular}{|l|c|}
\hline \multicolumn{1}{|c|}{ INTERNAL $\mathbf{~ X )}$} & NILAI \\
\hline Strength & 1.56 \\
\hline Weakness & 1.09 \\
\hline Selisih & 0.47 \\
\hline EKSTERNAL (n) & \\
\hline Opportunity & 1.55 \\
\hline Threat & 0.70 \\
\hline Selisih & 0.85 \\
\hline
\end{tabular}

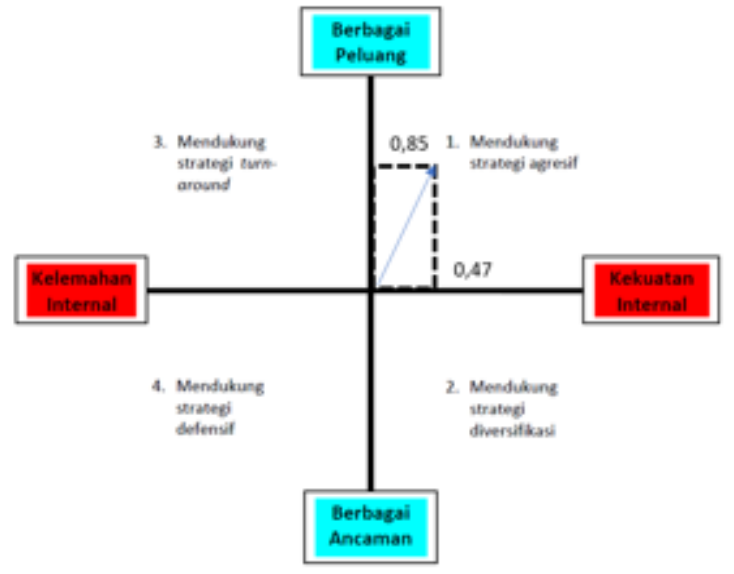

Hasil penghitungan analisis SWOT didapatkan bahwa koordinat berada di kuadran I merupakan situasi yang sangat menguntungkan. TNI AL memiliki peluang dan kekuatan sehingga dapat memanfaatkan peluang yang ada. Strategi yang harus diterapkan dalam kondisi ini adalah mendukung kebijakan pertumbuhan yang agresif. 
Tabel 13. Matriks SWOT

\begin{tabular}{|c|c|c|}
\hline IFAS/EFAS & $\begin{array}{l}\text { STRENGTHS (S) } \\
\text { (S1) Peraturan Kasal nomor } 3 \text { tahun } 2020 \\
\text { tentang Rekrutmen Bintara dan Tamtama } \\
\text { (S2) Pengawasan terhadap Tim Seleksi } \\
\text { (S3) Penunjukan Tim Pemeriksa/Penguji } \\
\text { sesuai dengan kompetensinya } \\
\text { (S4) Pakta Integritas dan Transparansi seleksi }\end{array}$ & $\begin{array}{l}\text { WEAKNESSES (W) } \\
\text { (W1) Kurangnya inovasi dalam } \\
\text { Sosialisasi penerimaan prajurit } \\
\text { TNI AL } \\
\text { (W2) Kompetensi pejabat } \\
\text { Personel } \\
\text { (W3) Tidak adanya Reward and } \\
\text { Punishment } \\
\text { (W4) Tidak adanya anggaran } \\
\text { khusus pembinaan calon } \\
\text { prajurit di Panda }\end{array}$ \\
\hline $\begin{array}{l}\text { OPPORTUNITIES (O) } \\
\text { (O1) Kemajuan Teknologi Informasi } \\
\text { (O2) Pembukaan Satdik Sorong } \\
\text { (O3) Jakren TNI AL } 2020 \text { Rekrutmen di wilayah } \\
\text { Indonesia Timur } \\
\text { (O4) Validasi Organisasi TNI AL }\end{array}$ & $\begin{array}{l}\text { STRATEGI S-O } \\
\text { Ciptakan strategi yang menggunakan } \\
\text { kekuatan untuk memanfaatkan peluang }\end{array}$ & $\begin{array}{l}\text { STRATEGI W-O } \\
\text { Ciptakan strategi yang } \\
\text { meminimalkan kelemahan } \\
\text { untuk memanfaatkan peluang }\end{array}$ \\
\hline $\begin{array}{l}\text { THREATHS (T) } \\
\text { (T1) Masyarakat belum mengenal keberadaan } \\
\text { TNI AL. } \\
\text { (T2) Minimnya animo pendaftaran dari } \\
\text { masyarakat setempat } \\
\text { (T3) Kesiapan calon peserta seleksi } \\
\text { (T4) Pengaruh OPM sehingga para pemuda } \\
\text { enggan menjadi TNI AL }\end{array}$ & $\begin{array}{l}\text { STRATEGI S-T } \\
\text { Ciptakan strategi yang menggunakan } \\
\text { kekuatan untuk mengatasi ancaman }\end{array}$ & $\begin{array}{l}\text { STRATEGI W-T } \\
\text { Ciptakan strategi yang } \\
\text { meminimalkan kelemahan dan } \\
\text { menghindari ancaman }\end{array}$ \\
\hline
\end{tabular}

Berdasarkan analisis SWOT diatas diperoleh nilai dengan bobot tertinggi berada pada (S1-O1), (S1$\mathrm{O} 2),(\mathrm{S} 1-\mathrm{O} 3)$ dan (S1-O4) sehingga dapat disusun strategi-strategi untuk menentukan pola rekrutmen prajurit TNI AL pada Satdik Sorong tahun 2020 sebagai berikut:

a. Strategi 1 (S1-O1). Dengan adanya Peraturan Kasal nomor 3 tahun 2020 tentang Rekrutmen Bintara dan Tamtama perlu dilaksanakan Sosialisasi penerimaan prajurit TNI AL dengan memanfaatkan kemajuan Teknologi Informasi dalam rangka peningkatkan animo pendaftar.

b. Strategi 2 (S1-O2). Dengan adanya Peraturan Kasal nomor 3 tahun 2020 tentang Rekrutmen Bintara dan Tamtama maka pembukaan Satdik Sorong dapat menarik minat masyarakat dalam rangka peningkatan animo pendaftar.

c. Strategi 3 (S1-O3). Dengan adanya Peraturan Kasal nomor 3 tahun 2020 tentang Rekrutmen Bintara dan Tamtama menjadi payung hukum dalam pelaksanaan kebijakan perencanaan TNI AL tahun 2020 untuk memfokuskan Rekrutmen di wilayah Indonesia Timur agar menarik minat masyarakat setempat untuk mendaftar menjadi calon prajurit TNI AL sehingga meningkatkan animo pendaftar. d. Strategi 4 (S1-O4). Dengan adanya Peraturan Kasal nomor 3 tahun 2020 tentang Rekrutmen Bintara dan Tamtama mendukung pelaksanan Validasi organisasi khususnya penyediaan prajurit TNI AL untuk mengisi ruang dan jabatan/DSP di KRI sehingga membutuhkan lebih banyak animo pendaftar yang akan di seleksi menjadi prajurit TNI AL.

Dari hasil penelitian yang diperoleh sebagaimana tersaji pada uraian pengolahan data menggunakan triangulasi berupa wawancara, observasi, dokumentasi, menentukan faktor eksternal dengan analisis data SWOT di atas, sebagai langkah lanjutan untuk membandingkan temuan penelitian dengan teori yang digunakan sehingga didapatkan jawaban dari rumusan masalah secara keseluruhan yaitu: pola rekrutmen Prajurit TNI AL pada Satuan Pendidikan Sorong dimulai dari kebijakan perencanaan TNI AL tahun 2020 yang memfokuskan pada rekrutmen di kawasan Timur Indonesia maka dibentuklah Satdik Sorong sebagai pusat pendidikan pertama di Sorong, Papua, oleh karena itu perlu dilaksanakan sosialisasi penerimaan prajurit TNI AL dengan memanfaatkan kemajuan Teknologi Informasi dalam rangka memberikan informasi dan menarik minat masyarakat setempat untuk mendaftar dan bergabung menjadi prajurit TNI AL yang akan 
mengisi ruang dan jabatan/DSP KRI di wilayah kerja Koarmada III karena adanya validasi organisasi TNI AL.

\section{KESIMPULAN}

Kesimpulan yang dapat ditarik dari hasil penelitian dan pembahasan tentang pola rekrutmen pada Satdik Sorong pada tahun anggaran 2020 adalah bahwa pola rekrutmen yang dlaksanakan pada tingkat daerah sudah sesuai dengan Keputusan Kepala Staf Angkatan Laut Nomor Kep/1401/VIII/2018 tentang Petunjuk referensif seleksi pendidikan pertama prajurit TNI Angkatan Laut. Proses penerimaan yang transparan dan diselenggarakan oleh panitia daerah maupun panitia tingkat pusat dapat terselenggara dengan baik sebab adanya penunjukan tim pemeriksa/penguji yang berkompeten dengan kualitas SDM yang unggul sehingga diperoleh calon prajurit TNI AL yang unggul yang dapat bekerja secara profesional dalam penugasannya di KRI yang beroperasi di wilayah kerja Komando Armada III. Pelaksanaan rekrutmen ini memberikan dampak positif pada pemenuhan personel di wilayah Indonesia Timur. Serta keberhasilan Satdik Sorong menjadi dasar terbentuknya 3 wilayah Satdik pada tahun 2021 yang terdiri dari Satdik 1 Tanjung Uban, Satdik 2 Makassar dan Satdik 3 Sorong.

Saran peneliti dengan dibentuknya Satdik Sorong tentunya membutuhkan Tim pemeriksa/ penguji yang berkompeten sehingga membutuhkan personel dengan kompetensi yang diperlukan sehingga dimohon kepada Disminpersal untuk melaksanakan pengisian ruang dan jabatan/DSP khususnya perwira dokter spesialis dan perwira jasmani. Kemudian untuk meningkatkan animo pendaftar diharapkan adanya inovasi dari Panda dalam melaksanakan sosialisasi penerimaan prajurit dengan memanfaatkan kemajuan media informasi sehingga TNI AL lebih dikenal oleh pemuda/pemudi Papua dan menarik minat mereka untuk bergabung menjadi prajurit TNI AL.

\section{DAFTAR PUSTAKA}

Bungin, Burhan. Penelitian Kualitatif. Jakarta: Kencana, 2011.

Creswell, John W. Research Design Pendekatan Kualitatif, Kuantitatif, dan Mixed. Yogyakarta: PT. Pustaka Pelajar, 2009.

Hasibuan, Malayu S.P. Manajemen Sumber Daya Manusia. Jakarta: PT. Bumi Aksara.2009.
Moleong, Lexy J. Metode Penelitian Kualitatif. Bandung: PT. Remaja Rosdakarya, 2018.

Nawawi, Hadari. Perencanaan Sumber Daya Manusia. Yogyajarta: Gajah Mada University Press, 2008.

Noor, Juliansyah. Metodologi Penelitian: Skripsi, Tesis, Disertasi, dan Karya Ilmiah. Jakarta: Kencana Prenamedia Group, 2012.

Riduwan. Metode dan Teknik Menyusun Tesis. Bandung: CV. Alfabeta, 2014.

Rivai, Veithzal dan Sagala. Manajemen Sumber Daya Manusia. Jakarta:

Rajawali Pers, 2015.

Rangkuti, Freddy. Tehnik Membedah Kasus Bisnis Analisis SWOT. Jakarta: PT. Gramedia Pustaka. 2017.

Sedarmayanti. Manajemen Sumber Daya Manusia. Bandung: PT. Refika Aditama, 2019.

Sinambela, Lijan Poltak. Manajemen Sumber Daya Manusia. Jakarta: PT. Bumi Aksara. 2015.

Sugiyono. Metode Penelitian Pendidikan, Pendekatan Kuantitatif, Kualitatif, dan $R \& D$. Bandung: CV. Alfabeta, 2016.

Sugiyono. Metode Penelitian Kualitatif (Untuk Penelitian yang Bersifat: Eksploratif, Enterpretif, Interaktif dan Konstruktif). Bandung: CV. Alfabeta, 2020.

Suharsimi, Arikunto. Prosedur Penelitian Suatu Pendekatan Praktek. Jakarta: PT. Rineka Cipta, 2006.

Sukidin dan Mundir. Metode Penelitian. Surabaya: Insan Cendekia, 2005.

Sudarwan, Danim. Menjadi Peneliti Kualitatif Rancangan Metodologi, Presentasi, dan Publikasi Hasil Penelitian untuk Mahasiswa dan Penelitian Pemula Bidang Ilmu Sosial, Pendidikan, dan Humaniora. Bandung: PT. Remaja Rosdakarya, 2002.

Yusuf, A Muri. Metode Penelitian Kuantitatif Kualitatif dan Penelitian Gabungan. Jakarta: Kencana Prenamedia Group, 2014.

Yuniarsih, Tjutju dan Suwatno. Manajemen Sumber Daya Manusia. Bandung: CV. Alfabeta, 2009. 